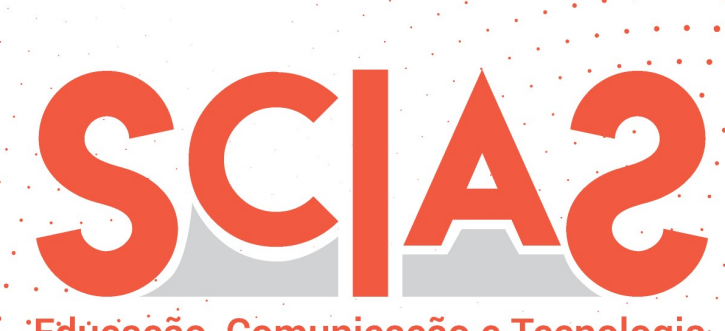

Educaçăão, Comunicação e Tecnologia

Atribuição BB CY 4.0

\title{
Recursos tecnológicos como possibilidades para a prática pedagógica
}

\author{
Caroline Duailibi Felício ${ }^{1}$ \\ Clarice Cardoso Valentim² \\ Maria Laura Moreira de Souza3 \\ Maria Luiza Moreira de Souza4 \\ Marcelo Diniz Monteiro de Barros5
}

${ }_{1}^{1}$ Graduanda em Pedagogia pela Universidade do Estado de Minas Gerais, no $7^{0}$ periodo. Atuação como estagiária remunerada no colégio Nossa Senhoras das Dores Unidade Pompeia em Belo Horizonte desde 2019.

Email: caroline.duailibi17@gmail.com

${ }^{2}$ Estudante de graduação em Pedagogia (2017-2020) e estagiária na Escola Virtual da Diretoria de Formação, Aperfeiçoamento e Pós-Graduação do Ministério Público de Minas Gerais (2019 - atual). Atuação como estagiária na Escola Judiciária Eleitoral de Minas Gerais (2018-2019) e como bolsista no Programa Institucional de Bolsas de Iniciação à Docência (2018-2020).

Email: claricecardosovalentim@gmail.com 3 Graduanda em Pedagogia pela Universidade do Estado de Minas Gerais, no $6^{\circ}$ periodo. Intercâmbista na Universidade do Porto em 2019, atualmente é estagiária remunerada no colégio Nossa Senhoras das Dores Unidade Pompeia em Belo Horizonte desde 2017.

Email: lalamdesouza@gmail.com

4 Iniciou a graduação de Ciências Sociais pela Universidade Federal de Minas Gerais, em 2018. Formada pela Escola Estadual Padre Menezes. Encontrou espaço na universidade para estar em contato com os questionamentos que já a acompanhavam desde sua formação, no ensino médio, em uma escola humanista. As mais diversas experiências, como o intercâmbio cultural realizado na Itália, em 2014, foram marcantes para sua formação e trajetória enquanto sujeito no mundo.

Email: maluzinhamoreira84@gmail.com

5 Professor do Departamento de Ciências Biológicas da Pontifícia Universidade Católica de Minas Gerais, da Faculdade de Educação da Universidade do Estado de Minas Gerais e do Programa de Pós-Graduação em Ensino em Biociências e Saúde - Instituto Oswaldo Cruz - Fiocruz

Email: marcelodiniz@pucminas.br 


\section{Resumo}

O presente trabalho, a partir de uma pesquisa bibliográfica sobre recursos tecnológicos e educação, pretende provocar a reflexão sobre o uso destas ferramentas como estratégias didáticas que proporcionem aprendizagens significativas aos educandos. Para esta discussão, autores como Freire, Sancho e Ausubel fomentam, junto às normas educacionais vigentes, os conceitos e as perspectivas de um ensino significativo e práticas pedagógicas promotoras de uma participação ativa do educando no processo de aprendizagem. O professor, mediador, e o aluno, protagonista, se envolvem na construção do conhecimento, ressignificando as práticas escolares. Nesse sentido, é sabido que a adoção de recursos tecnológicos, ainda hoje, é um grande desafio aos docentes que não estão preparados, cabendo reconhecer a necessidade de cursos de formação inicial e continuada para incentivar e conscientizar quanto ao uso de tecnologias para auxiliarem na melhoria da qualidade da educação.

\section{Palavras-chave}

Recursos tecnológicos. Educação. Aprendizagem significativa.

Recebido em: 30/04/2020

Aprovado em: 25/06/2020

\section{Technological resources as possibilities for pedagogical practice}

\section{Abstract}

The present work, based on a bibliographical research on technological resources and education, aims to provoke reflection on the use of these tools as didactic strategies that provide significant learning to students. For this discussion, authors such as Freire, Sancho and Ausubel promote, together with the current educational norms, the concepts and perspectives of meaningful teaching and pedagogical practices that promote an active participation of the student in the learning process. The teacher, mediator and the student, protagonist, engage in the construction of knowledge, resignifying school practices. In this sense, it is recognized that the adoption of technological resources, even today, is a great challenge for teachers who are not sufficiently prepared, and it is necessary to recognize the need for initial and continuous training courses to encourage and raise awareness about the use of technologies to assist in improving the quality of education.

\section{Keywords}

Technological resources. Education. Significant learning. 


\section{Introdução}

Estamos vivenciando grandes mudanças no século XXI, influenciadas pelas tecnologias, que transformam vários contextos como cotidiano, trabalho, economia, relacionamentos e, principalmente, o acesso ao conhecimento a partir das Tecnologias da Informação e Comunicação (TICs ou TDICs). As escolas, não alheias a tais modificações, devem se adaptar a esta era tecnológica, buscando inserir e valorizar a utilização das TICs como estratégia didática.

O processo de ensino-aprendizagem deve proporcionar ao aluno uma experiência significativa - entendida aqui como uma aprendizagem que provoca uma modificação no aluno, que pode ser aplicada à prática, bem como levar à reflexão sobre o status quo em que o aluno se encontra. É a partir dessa relação aluno-escola que o ensino atingirá seu caráter fundamental, desenvolvendo o senso crítico, interesse, participação, autonomia e dedicação aos processos escolares e às suas possibilidades. Este objetivo pode ser atingido se a instituição, através de recursos audiovisuais como filmes, vídeos e animações, trabalhar temas relevantes para a criança. Algo que comumente é transmitido ao aluno, passa a ser vivenciado, internalizado e aprendido pelo discente.

As escolas podem ser entendidas como espaços privilegiados para a inserção e valorização de recursos tecnológicos como estratégias didáticas, uma vez que proporciona aprendizagens que não serão desenvolvidas em outros locais. Isto pode ocorrer por meio da utilização de ferramentas que estão presentes na vida dos educandos, reinventando seus usos e otimizando a qualidade da educação. Tal utilização é defendida pela Base Nacional Comum Curricular (BNCC, 2017) e Lei de Diretrizes e Bases da Educação Nacional (LDBEN, Lei nº 9394, 1996), além de ser questão latente nos cursos de formação, que envolvem a capacidade docente para utilizar a tecnologia em prol das práticas educativas.

A LDBEN, promulgada em 1996, é a legislação que direciona e orienta a educação nacional. Estabelece, em seu artigo $3^{06}$, inciso IX, treze princípios

6Título II, seção “Dos Princípios e Fins da Educação Nacional” (LDBEN, Lei nº 9394, 1996). 
fundamentais para o ensino, que visam alcançar o pleno desenvolvimento do educando para o exercício da cidadania e a qualificação profissional. $\mathrm{O}$ documento aponta, em seu princípio IX, a garantia de padrão de qualidade da educação e assim, espera-se que toda a educação básica consiga alcançar um nível mínimo de qualidade, visando minimizar a diferença de oportunidades entre as instituições públicas e privadas. Todos, sem distinção, devem ter oportunidades de aprender conteúdos com e de qualidade, como versa a Constituição Federal de 1988 (CF), podendo estas ocorrerem através da utilização de diferentes estratégias didáticas e adoção de variadas metodologias, como a ludicidade, recursos visuais, sonoros e tecnológicos.

Neste contexto social, em que a tecnologia torna-se cotidiana, cabe ao professor ressignificar e ampliar suas práticas pedagógicas, implementando as novas TICs, contribuindo para uma aprendizagem mais significativa. Entende-se como aprendizagem significativa, segundo Rogers citado por Klausen:

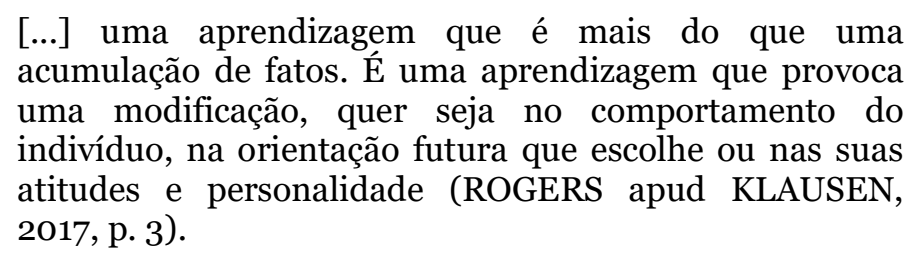

Para isto, é necessário romper com práticas pedagógicas de exposição de conteúdos, aprendizagens mecanizadas, em que os alunos são sujeitos passivos, devendo apenas reproduzir os conteúdos sem participar efetivamente do processo de aprendizagem, que se traduz em uma prática conhecida como "educação bancária", muito criticada por Freire (1991), que defendia o protagonismo dos educandos nos processos educativos. É fundamental proporcionar aprendizagens significativas que valorizem o ativismo dos sujeitos em aulas, considerando a "bagagem cultural" de cada indivíduo associando e produzindo novos conhecimentos, transformando e ampliando as perspectivas dos educandos, assim como defendido por Ausubel (BRASIL, 2019).

Nesse viés, é importante considerar o conhecimento prévio dos alunos associado ao uso de diversos recursos (vídeos, apresentações, internet), quando mediados pelos professores, como possibilidades em sala de aula, pois permite uma interação, participação e elaboração de trocas entre aluno e conhecimento. 
O presente trabalho tem como objetivo evidenciar a importância de inclusão da cultura digital, presente e operante na realidade dos alunos, às práticas didáticas, no intuito de promover uma aprendizagem interessante e contextualizada. A metodologia é a pesquisa bibliográfica, através de análises de livros, normas nacionais e artigos relacionados à temática estudada, destacando os autores: Paulo Freire, David Ausubel e Sancho, que foram imprescindíveis para a compreensão e elaboração deste estudo.

\section{O uso de recursos tecnológicos como estratégias didáticas}

A tecnologia está presente de forma ativa e efetiva na sociedade atual. Não por acaso, esta é considerada a era tecnológica. Por esta razão, há uma preocupação em formar profissionais aptos para lidar com esta nova configuração social. Entre as ocupações que mais terão demandas relacionadas à tecnologia, está a carreira de magistério (DOT Digital Group, 2019). Assim, as Diretrizes Curriculares Nacionais para o Curso de Pedagogia abordam, em suas orientações, a formação de professores para que ofereça "ênfases nos percursos de formação dos graduandos [...] para contemplar, entre muitos outros temas [...] a educação a distância e as novas tecnologias de informação e comunicação aplicadas à educação" (BRASIL, 2006, p. 4), uma vez que o público principal é formado por nativos digitais7.

Surge, neste ponto, a questão motivadora de debates da educação: deve-se ensinar a utilizar os recursos tecnológicos ou ensinar através destes? A resposta pode ser positiva para as duas indagações, uma vez que há estratégias didáticas que abrangem a utilização na educação e a educação para a utilização.

O conceito de tecnologia pode ser entendido e expresso de várias maneiras. Para McLuhan (1969), tecnologia é a extensão do corpo, algo que proporciona realizar determinada função que, anteriormente, encontrava algum impeditivo.

\footnotetext{
${ }^{7}$ Nativos digitais são pessoas nascidas imersas na era de recursos tecnológicos e digitais, sendo naturalmente expostas a tais ferramentas. Por este motivo, têm grande facilidade em manipulá-las. As gerações Z (ou Centennials), composta por indivíduos nascidos entre 1996 e 2010 e a Alpha, vindos depois de 2010, são exemplos de nativos digitais. (DOT DIGITAL GROUP, 2019).
} 
Pastor (1998) defende, por outro lado, que a tecnologia pode auxiliar a sociedade na medida em que proporciona algumas possibilidades de comunicação, aprendizagem, expressão. A partir dessa concepção, pensaremos os recursos tecnológicos como a aparelhagem que permite reproduzir conteúdos em tempo real, jogos interativos, desenhos, animações e apresentações.

Desde os anos 70, com a consolidação da informática, os computadores foram incorporados de vez à educação. Esta aproximação abriu caminho para as demais tecnologias que, em certa medida, revolucionaram a aquisição de conhecimentos. Na década seguinte, surgem as Novas "Tecnologias da Informação" (NTICs), que consistem em opções de obtenção de informações e comunicação através das máquinas. De acordo com Sancho (2001), as técnicas mecânicas podem ser incorporadas ao saber de forma completa, ou seja, o saber e a tecnologia não são opostos e sim complementares. Dessa maneira a tecnologia fundamenta a ciência quando oferece aplicação prática.

A educação é categoria e por isso tem potencial transformador tanto para aquele que age por ela como por aquele que se permite aprender por ela, visto que, para Sancho (2001), a educação exige troca de conhecimento, habilidades e técnicas. As escolas, portanto, carregam a finalidade de realizar uma tarefa educacional. É necessário compreender que todos os educadores utilizaram, utilizam e utilizarão algum tipo de tecnologia em suas aulas. Isso vale para todos os ofícios que se propõem transformar o meio em que atuam. Esse raciocínio prova que a concepção de tecnologia não contempla somente as máquinas, aparelhos ou ferramentas informáticas. A tecnologia presente nas salas de aula caracteriza-se também com os livros, as aulas expositivas, jogos pedagógicos, a relação professor-aluno e o desenvolvimento particular do educando.

A tecnologia permitiu o acesso a grandes volumes de informação em tempo otimizado e o aumento da precisão de trabalhos. O computador, segundo Solomon (1987), pode ser visto como livro-texto, em que se assemelha ao livro didático, mas agrega uma função interativa, bem como meio de expressão. É 
neste contexto que surgem os softwares $\boldsymbol{8}$ interativos, os jogos educativos, os livros digitais. Estas ferramentas buscaram, a partir da modificação da sociedade, incorporar à educação tecnologias, buscando atrair a atenção e o ativismo dos alunos.

Estabelecendo novas relações humanas e sociais, Pierre Lévy (1999), corroborando com as ideias de Valente e Mattar (2007), discorre sobre a função do professor no processo de gerenciar o uso das TICs para a aprendizagem, que passa de difusor de conhecimentos para promotor da centralidade do educando: "[...] sua competência deve deslocar-se no sentido de incentivar a aprendizagem e o pensamento. [...]” (LÉVY, 1999, p. 155). Portanto, o professor deve fornecer aos estudantes a assistência para que as TICs sejam utilizadas como mecanismos auxiliares às práticas pedagógicas, não como elementos centrais.

É possível perceber, portanto, que o contexto educacional está inserido em uma sociedade e em relações construídas por sujeitos históricos, dinâmicos. A tecnologia, utilizada como meio, requer a aproximação das práticas educativas, das pessoas e dos conhecimentos. Imersos neste contexto, as crianças e os jovens buscam aparatos tecnológicos também na escola, pois estes fazem parte de seus cotidianos.

\section{As tecnologias como vivências dos educandos e sua importância nas práticas pedagógicas}

"O corpo individual funciona como uma extensão das tecnologias globais de comunicação"

(PRECIADO, Testo Junkie, 2018, p. 47)

Segundo Preciado (2018), os corpos desta geração se mostram num constante fazer estendido às máquinas e suas evoluções. $\mathrm{O}$ virtual intercepta a realidade $\mathrm{e}$ não opera dissociado para os seres que vivenciam a era cibernética desde a primeira infância. A comunicação, a velocidade, a forma do pensar, a linguagem e a própria interação com a realidade material são reinventadas com o uso da tecnologia. A compreensão que se faz acerca da realidade é atravessada por

8Programas ou conjuntos de instruções que controlam e direcionam o funcionamento de aplicações do computador; suportes lógicos de programas/atividades. 
informações constantes em todas as direções e sentidos. A escola, organismo que responde à sociedade em nível micro, não está isenta a estas configurações.

Para entender melhor a importância da atualização dos recursos educativos, deve-se compreender certos conceitos-chaves da relação humano-máquina que se reconfigura e internaliza abruptamente. Já não se trata de um debate acerca da validade da tecnologia no ensino, mas de uma adequação à realidade prática dos sujeitos contemporâneos. O debate que se cria na atualidade, gira ao redor do âmbito prático, que reflete e emerge no contexto escolar. Como? Nesse sentido, afirma Almeida, citado por Pereira:

\begin{abstract}
Os alunos por crescerem em uma sociedade permeada de recursos tecnológicos, são hábeis manipuladores da tecnologia e a dominam com maior rapidez e desenvoltura que seus professores. Mesmo os alunos pertencentes a camadas menos favorecidas têm contato com recursos tecnológicos na rua, na televisão, etc., e sua percepção sobre tais recursos é diferente da percepção de uma pessoa que cresceu numa época em que o convívio com a tecnologia era muito restrito. (ALMEIDA apud PEREIRA, 2008, p. 14)
\end{abstract}

Compreender a reformulação da realidade virtual como uma espécie de rede tecno viva que dialoga entre si, criando redes sociais, conteúdo, mídia, ciberidentidades, linguagens, espaços, que permeiam e alteram o mundo real em suas formas de se fazer experienciar, é entender e empreender a presença da virtualidade em nossas materialidades e suas respectivas mudanças e demandas pedagógicas (SILVA, 2016). A introdução dessas práticas na educação atualmente significa a aproximação de realidades e fortalece o vínculo escola/aluno, ressignificando o ambiente e a prática escolar como um todo. A cultura tecnológica nas escolas carrega consigo o potencial de transformar a relação dos alunos com a produção do saber e das possibilidades das TICs, de tornar este processo construtivo, nas quais o educando se encontra representado como sujeito ativo que participa da aprendizagem.

A reconfiguração das formas e velocidades do pensar, a virtualização da realidade, a cultura digital, as múltiplas formas de linguagem que se mostram acessíveis através da internet, as diversas formas de linguagem a serem exploradas (experimentações lúdicas artísticas), são reflexos da atualidade e demandas às práticas pedagógicas. 
Portanto, é válida a análise das múltiplas possibilidades que as TICs proporcionam quando se pensam formas horizontais da relação entre aluno, professor e conhecimento, nas quais há um engajamento e protagonismo do educando nas atividades - no sentido de produzir uma aprendizagem significativa, isto é, a apropriação dos conteúdos para que sejam aplicados à realidade de forma prática.

\section{Aprendizagens significativas através do uso de recursos tecnológicos}

Historicamente, a figura e a relação professor-aluno vem sendo ressignificada devido às mudanças políticas, sociais, culturais e econômicas, que refletem em novas concepções de ensino-aprendizagem. Um marco que altera as concepções de educação é o movimento Escola Nova9, que defende a valorização da singularidade do sujeito, do pluralismo de ideias, da diversidade de opiniões e da participação dos educandos na construção do conhecimento, vendo o aluno como sujeito ativo.

Isto exige que o educando tenha autonomia para intervir, refletir criticamente e ser protagonista de seu aprendizado, participando das aulas, valorizando uma prática dialógica e de troca de saberes entre este e professores, rompendo com a prática de ensino que vigorava anteriormente, em que o professor é a figura central do processo de ensino-aprendizagem e único detentor de saberes. Assim, substitui-se práticas tradicionais de ensino por concepções progressistas, ou seja, práticas pedagógicas significativas para os alunos, que promovam a conscientização e a capacidade de intervenção e transformação das realidades por meio da consolidação de novos conhecimentos.

Segundo David Ausubel (2000), a aprendizagem significativa depende da interação entre conhecimentos novos, prévios e cognição. Esta implica na participação dos alunos como sujeitos e na valorização de suas experiências prévias (subsunçores). Para Gomes et al (2008), para que a aquisição (ou ancoragem) de conhecimentos seja realmente significativa, é necessário que a

9 Movimento de renovação das concepções de ensino na primeira metade do século XX, cujo pressuposto norteador era o papel ativo dos alunos. 
experiência anterior seja considerada, devendo intensificar e complexificar os conteúdos à medida que são trabalhados.

A aprendizagem significativa visa desenvolver a capacidade do aluno em aplicar conhecimentos de forma prática em atividades complexas. O conhecimento consolidado é aplicado em diversas áreas, não se limitando a disciplinas específicas. Por esta razão, a abordagem tradicional torna-se oposta à aprendizagem significativa. A atividade mecânica, metodologia da educação tradicional, ainda que necessária em alguns momentos, torna-se mera repetição, sendo esquecida ou perdida mais rapidamente. Enquanto o aprendizado é pautado no professor e no fracasso do aluno (abordagem tradicional), a aprendizagem significativa parte do aluno e suas experiências, sendo interdisciplinar e aplicável no cotidiano.

Tal aprendizagem não ocorre com conhecimentos isolados e aleatórios. Aqueles que são relevantes para o processo de aquisição ou consolidação de saberes são trabalhados, ampliando e dando novos significados à aprendizagem. Como esta metodologia valoriza e pressupõe construções anteriores, o aluno tende a apreender de forma mais efetiva. Para Ausubel (2000),

"A aprendizagem significativa não é sinônimo de aprendizagem de
material significativo. Em primeiro lugar, o material de aprendizagem
apenas é potencialmente significativo. Em segundo, deve existir um
mecanismo de aprendizagem significativa" (AUSUBEL, 2000, p. 1,
grifo do autor).

Para que a aprendizagem significativa ocorra, o aprendiz deve ter predisposição para aprender, o que infere "uma predisposição para relacionar-se com novos conhecimentos atribuindo significados” (BRASIL, 2019).

Diante desses preceitos, os docentes contribuem para romper com a prática tradicional de ensino reformulando, de forma crítica e inovadora, a metodologia de ensino pautada na memorização, na mera cópia e reprodução de conhecimentos. Desta maneira, as novas posturas promovem a desconstrução da visão de ensino da "tábula-rasa", criticada por Freire (2001) - o professor visto como o único detentor do conhecimento, cabendo ao aluno apenas 
reproduzir os saberes nas avaliações, sem participar efetivamente da construção coletiva.

A partir do uso de recursos tecnológicos, são proporcionadas aulas mais contextualizadas e dinâmicas, em que os educandos participam realmente do processo coletivo e contínuo de ensino-aprendizagem, contribuindo para a formação de alunos conscientizados, protagonistas, capazes de refletir, participar, transformar e intervir em seus contextos, valorizando o potencial crítico e criativo de cada indivíduo - finalidade da educação.

Concordando, assim, com as ideias de Freire (1996), "Educar é impregnar de sentido o que fazemos a cada instante". Ou seja, é papel do professor possibilitar oportunidades de aprendizagem reais, mais atrativas, prazerosas, interessantes e facilitadoras no processo de ensino-aprendizagem para seus alunos diariamente, através do reconhecimento de experiências prévias dos alunos, mediado pelo uso dos recursos tecnológicos como forma de alcançar aprendizagens significativas.

\section{O uso de recursos tecnológicos segundo a Base Nacional Comum Curricular}

O uso de tecnologias nas salas de aula é uma prática defendida também na Base Nacional Comum Curricular (BNCC), que reconhece que estas já são ferramentas presentes na vida de grande parte dos alunos, seja através da televisão, da internet, jogos, celulares ou tablets. Por isso, cabe às escolas acompanhar tais atualizações e implementá-las nas salas de aulas, reconhecendo o potencial desses recursos enquanto estratégias didáticas que enriquecem e tornam a aprendizagem dos alunos mais significativa, dinâmica e interessante.

Para isto, a BNCC define o uso de tecnologias como uma competência fundamental, denominada "cultura digital", a ser desenvolvida em toda a educação básica, perpassando de forma transversal todas as disciplinas, visando contribuir para o desenvolvimento integral dos educandos e a consolidação do 
"pensamento crítico, criativo e lógico, o desenvolvimento motor e a linguagem" (BNCC, 2017, p. 7).

A cultura digital, como competência da BNCC, pretende que o aluno consiga:

Compreender, utilizar e criar tecnologias digitais de informação e comunicação de forma crítica, significativa, reflexiva e ética nas diversas práticas sociais (incluindo as escolares) para se comunicar, acessar e disseminar informações, produzir conhecimentos, resolver problemas e exercer protagonismo e autoria na vida pessoal e coletiva(BRASIL, 2017, p. 7).

O documento normativo supracitado valoriza e incentiva o uso das TICs como forma da escola acompanhar e estar contextualizada com a realidade em que os alunos já estão inseridos e associa o potencial pedagógico de proximidade que as tecnologias oferecem no processo de ensino-aprendizagem dos educandos. Assim como defendido na BNCC:

[...] o professor não precisa ser o detentor do conhecimento técnico sobre o uso das ferramentas disponíveis, mas sim o mediador que vai auxiliar os estudantes na reflexão sobre os melhores usos possíveis das TDICs (BRASIL, 2017).

Nesse sentido é papel do professor apresentar as TICs como facilitadoras no acesso ao conhecimento disponível. A partir do uso de vídeos, computadores, slides em sala, desenvolvem-se aulas mais interativas, que instigam o interesse através da maior participação e protagonismo dos educandos. Por fim, são proporcionadas aprendizagens significativas, convívio e domínio com as novas ferramentas tecnológicas, já disponíveis na maioria dos extratos sociais.

Nesse novo contexto da educação, é importante destacar que esta competência pedagógica estabelecida pela BNCC (2017) ainda é uma demanda desafiadora para muitos docentes, que enfrentam dificuldades ao pensar em como utilizar tais recursos tecnológicos em suas práticas pedagógicas e quais são os meios mais adequados para contribuir para a aprendizagem significativa dos alunos.

\section{Desafios aos docentes quanto ao uso dos recursos tecnológicos em salas de aula}

"O homem, como um ser histórico, inserido num permanente movimento de procura, faz e refaz o seu saber" (FREIRE, 1981, p. 47) 
É preciso compreender os recursos tecnológicos como parte de todo o processo educacional, como afirma Kenski:

Por mais que as escolas usem computadores e internet em suas aulas, estas continuam sendo seriadas, finitas no tempo, definidas no espaço restrito das salas de aula, ligadas a uma única disciplina e graduadas em níveis hierárquicos e lineares de aprofundamento dos conhecimentos em áreas específicas do saber (KENSKI, 2007, p. 45).

Como uma das formas de quebrar a segmentação da educação com a tecnologia é possível citar exemplos práticos, como aulas de robótica, laboratórios interativos, aulas de informática interdisciplinares, jogos e softwares online e gratuitos, projetores para exibir em grande escala mapas nas aulas de geografia, filmes e desenhos. Estas ferramentas podem tornar as aulas mais atraentes e permitir que os alunos compreendam os conteúdos de uma maneira mais real.

No entanto, existem problemas a serem solucionados na educação para que estes possam ser vistos não apenas como recursos, mas como estratégia pedagógica necessária para possibilitar aprendizagens mais dinâmicas, prazerosas e significativas. Logo, é possível notar que alguns educadores possuem resistência em utilizar esses meios, como demonstra Mercado:

\begin{abstract}
A resistência de muitos professores em usar as novas tecnologias na pesquisa pessoal e na sala de aula tem muito a ver com a insegurança derivada do falso receio de estar sendo superado, no plano cognitivo, pelos recursos instrumentais da informática. Nesse sentido, o mero treinamento para o manejo de aparelhos, por mais importante que seja, não resolve o problema. Por isso, é sumamente importante mostrar que a função do professor competente só não está ameaçada, mas aumenta em importância. Seu novo papel já não será o da transmissão de saberes supostamente prontos, mas o de mentores e instigadores ativos de uma nova dinâmica de pesquisa-aprendizagem (MERCADO, 2004, p. 13).
\end{abstract}

Valer-se de um ensino onde existe a diversidade tecnológica pode promover maior desenvolvimento cognitivo, criativo, de expansão de outros conhecimentos, através do contato com várias tecnologias e maior interação entre professor e aluno. Ou seja, desenvolve-se um ambiente educacional propício para o ensino significativo, onde o educador pode realizar um trabalho contextualizado com a realidade dos alunos.

Entretanto, para o alcance de aprendizagens significativas através da implementação de recursos tecnológicos nas salas de aulas, dentre outros 
mecanismos, observa-se um novo desafio aos docentes: a falta de capacitação, domínio e conhecimento sobre como utilizar estas ferramentas nas escolas, assim como afirma Tedesco:

\begin{abstract}
A diversificação dos lugares de produção de conhecimento e a necessidade da educação permanente provocaram uma expansão notável tanto dos âmbitos de formação como dos tipos de educadores. Além dos meios de comunicação, surgiram novos docentes a partir da atividade produtiva e social. (TEDESCO, 2001, p. 27).
\end{abstract}

Nessa nova configuração, é visível a demanda de formação e capacitação para que os professores aprendam a dominar e tomar consciência da importância e benefícios do uso de recursos tecnológicos para promover aprendizagens significativas. É indispensável a mediação de diferentes ferramentas que potencializem a aprendizagem, atraindo o aluno, imerso numa cultura digital, com conhecimentos prévios - que devem ser valorizados na escola, reconhecendo-o como sujeito ativo. O professor, mediando as atividades, está em interação com conhecimentos, recursos tecnológicos e discentes.

Nesse sentido, cabe aos professores estar em contínua aprendizagem, transformando suas práticas pedagógicas, aplicando conhecimentos adquiridos em sua formação inicial, acompanhados de estratégias de ensino pertinentes com a realidade de seus alunos. Ou seja, o professor não deve ensinar sobre ciências hoje adotando a mesma estratégia didática que utilizava há 20 anos. É necessário que ele esteja em um processo constante de "inconclusão e inacabamento", ideias defendidas por Freire (1991), que propõe a necessidade de todos os sujeitos estarem em constante aprendizagem, numa evolução diária, entre erros e acertos, ressignificando diariamente suas práticas como sujeitos em contínuo processo de desenvolvimento. Para isto, cabe ao professor ter a consciência de reinvenção, buscando aperfeiçoamentos, rompendo com práticas fixas, acabadas e tradicionais, e implementando novos saberes através do manuseio de ações oferecidas pela realidade, que se reformula constantemente. Diante das transformações tecnológicas que a sociedade perpassa, é importante que o professor esteja atento e considere tantos outros desafios que a tecnologia nos apresenta: quais tecnologias estão disponíveis para os professores? De que forma o uso destas contribui para a aprendizagem? As tecnologias adotadas são 
acessíveis para os alunos? Estas questões devem ser consideradas pelo professor no momento do planejamento da aula. Assim, Faria propõe que:

Planejar uma aula com recursos de multimeios exige preparo do
ambiente tecnológico, dos materiais que serão utilizados, dos
conhecimentos prévios dos alunos para manusear estes recursos, do
domínio da tecnologia por parte do professor, além de seleção e
adequação dos recursos à clientela e aos objetivos propostos pela
disciplina (FARIA, 2004, p. 59).

Para tanto, é evidente a necessidade de aprendizagem contínua e atualizada dos docentes para que, assim, possibilitem aulas dinâmicas e contextualizadas com a nova era tecnológica, adotando práticas que instiguem e desafiem o interesse, a curiosidade e a participação dos alunos no processo de construção de saberes de forma significativa, colaborando para a formação de sujeitos protagonistas, que possam intervir e transformar seus contextos.

\section{Considerações finais}

A partir das leituras e discussões propostas neste trabalho, pode-se perceber que a tecnologia, apesar de comum e efetiva na sociedade, encontra resistências e desafios em âmbito escolar. Para os docentes, é necessário a familiarização com recursos tecnológicos, visto que muitos não nasceram nesta configuração de era tecnológica ou digital. Para os alunos, a aprendizagem significativa e a participação ativa não são ações corriqueiras nas práticas escolares.

Dessa forma, é preciso refletir sobre o uso dos recursos tecnológicos na escola, considerando o educando como um sujeito ativo, influenciado pelo momento digital em que vive, carregado de bagagens culturais e conhecimentos prévios. $\mathrm{O}$ professor deve, de forma a facilitar e favorecer o processo de ensinoaprendizagem, utilizar os recursos tecnológicos que dispõe, pensando nas possibilidades e limitações que oferecem.

Para que as ferramentas sejam potencializadas em sua utilização, a formação de professores deve abarcar o uso de recursos tecnológicos, como defendido pelos documentos BNCC (2017), LDBEN (1996) e Diretrizes Curriculares Nacionais para o Curso de Pedagogia (2006). Por fim, devem reconhecer e promover a formação continuada aos docentes, ressignificando as práticas pedagógicas. Tais 
medidas visam promover um ensino de qualidade e contextualizado, que proporcione uma participação ativa e reflexiva do educando, e um processo de ensino-aprendizagem colaborativo e significativo, almejando uma formação crítico-reflexiva, sujeitos conscientizados e protagonistas neste novo cenário tecnológico.

\section{Referências}

AUSUBEL, David P. Aquisição e Retenção de Conhecimentos: uma perspectiva cognitiva. Tradução de Lígia Teopisto. Lisboa: Paralelo Editora, 2000.

BRASIL. Aprendizagem significativa: breve discussão acerca do conceito. 2017. Disponível em: <http://basenacionalcomum.mec.gov.br/implementacao/praticas/caderno-depraticas/aprofundamentos/191-aprendizagem-significativa-breve-discussaoacerca-do-conceito>. Acesso em 19 abr 2020.

BRASIL. Base Nacional Comum Curricular. 2017. Disponível em: <http://basenacionalcomum.mec.gov.br/>. Acesso em 15 abr 2020.

BRASIL. Constituição da República Federativa do Brasil de 1988. 1988. Disponível

em: <http://www.planalto.gov.br/ccivil_03/constituicao/constituicao.htm>. Acesso em 15 abr 2020.

BRASIL. Diretrizes Curriculares Nacionais para o Curso de Pedagogia. 2006. Disponível em: <http://portal.mec.gov.br/cne/arquivos/pdf/pcpo5_05.pdf>. Acesso em 16 abr 2020.

BRASIL.Lei $n^{o}$ 9.394, de 20 de dezembro de 1996. 1996. Disponível em: <http://www.planalto.gov.br/ccivil_o3/leis/l9394.htm>. Acesso em 15 abr 2020.

DOT Digital Group. As gerações e suas formas de aprender. 2019. Disponível em: <http://conteudo.dotgroup.com.br/ebook-geracoes>. Acesso em: 05 out. 2019).

FARIA, E. T. O professor e as novas tecnologias. In: ENRICONE, Délcia (Org.). Ser professor. 4 ed. Porto Alegre: EDIPUCRS, 2004.

FREIRE, Paulo. A educação na cidade. São Paulo: Cortez, 1991.

FREIRE, Paulo. Educação como prática da liberdade. Rio de Janeiro: Paz e Terra, 1981.

FREIRE, Paulo. Medo e ousadia: o cotidiano do professor. Ed. Paz e Terra, 1996. 
FREIRE, Paulo. Pedagogia do Oprimido. 31. ed. Rio de Janeiro: Paz e Terra, 2001.

GOMES, Andréia Patrícia et al. A Educação Médica entre mapas e âncoras: a aprendizagem significativa de David Ausubel, em busca da Arca Perdida. Revista Brasileira de Educação Médica, vol. 32, $\mathrm{n}^{\circ}$ 1, Rio de Janeiro, jan-mar, 2008.

KENSKI, V. M. Educação e Tecnologia: O novo ritmo da informação. 2. ed. Campinas: Papirus, 2007.

KLAUSEN, Luciana dos Santos. Aprendizagem significativa: um desafio. XIII Congresso Nacional de Educação. Paraná, 2017.

LÉVY, Pierre. Cibercultura. Rio de Janeiro: Editora 34, 1999.

MCLUHAN, Marshall. Os meios de comunicação como extensões do homem. São Paulo: Cultrix, 1969.

MERCADO, Luís Paulo Leopoldo (Org.). Tendências na utilização das tecnologias da informação e comunicação na educação. Maceió: EDUFAL, 2004 .

PASTOR, Carmen Alba. Utilização didática de recursos tecnológicos como resposta à diversidade. In: SANCHO, Juana María (Org.). Por uma tecnologia educacional. Porto Alegre: Artmed, 1998.

PEREIRA, Bernadete Terezinha. $O$ uso das Tecnologias da Informação $e$ Comunicação na prática pedagógica da escola. 2008. Disponível em: <http://www.diaadiaeducacao.pr.gov.br/portals/pde/arquivos/1381-8.pdf $>$.

Acesso em 16 abr 2020.

PRECIADO, Paul B. Testo Junkie: sexo, droga e biopolítica na era farmacopornográfica.São Paulo: n1- edições, 2018.

SANCHO, Juana María. (Org.). A tecnologia: um modo de transformar o mundo carregado de ambivalência. Para uma tecnologia educacional. 2 ed. Porto Alegre: Artmed, 2001.

SILVA, Marco Polo Oliveira da. Youtube, juventude e escola em conexão: a produção da aprendizagem ciborgue. 2016. 172 f. Dissertação (Mestrado) Programa de Pós-Graduação em Educação, Universidade Federal de Minas Gerais, Belo Horizonte, 2016.

SOLOMON, C. Entornos de aprendizagem com ordenadores. Barcelona: Paidós, M.E.C, 1987.

TEDESCO, Juan. Carlos. O novo pacto educativo: educação, competitividade e cidadania na sociedade moderna. Tradução de Otacílio Nunes. São Paulo: Ática, 2001. 
VALENTE, Carlos; MATTAR, João. Second Life e Web 2.o na Educação: o potencial das novas tecnologias. São Paulo: Novatec, 2007. 